was one of the most vivid experiences of this kind.

P. W. Riegert has assembled the historical data on grasshopper abundance in Saskatchewan, up to 1966." Most readers will probably be unaware of the methodology of grasshopper surveys and forecasts. Most of the literature on this is not generally available, but Dr. Riegert's work includes a good treatment of this subject.

\section{MOVEMENT OF SPRING PEEPERS}

\author{
By WALTER KRIVDA, \\ Box 864, The Pas, Man.
}

On the night of August 1, 1975, while returning to town from Lake Atikameg by car, hundreds of spring peepers (Pseudacris negrita septentrionalis) were seen in the car headlights crossing the asphalt highway. A section of the highway about 100 meters long was covered by hundreds of the small frogs - all one species. They were coming out of the west ditch of the highway and moving in only one direction - east. Many were crushed by the passing traffic. Only three specimens were collected; they are preserved in writer's collec-
IPARKER, J. R., R. C. NEWTON and R. L. SHOTWELL. 1955. Observations on inass flights and other activities of the migratory grasshopper. USDA Tech. Bull. 1109.

"RIEGERT, P. W. 1968. A history of grasshopper abundance surveys and forecasts of outbreaks in Saskatchewan. Memoirs of the Ent. Soc. of Canada, No. 52.

"VIGOR, S. H. 1941. History of organized grasshopper campaigns in Saskathewan from 1919 to 1940. (Unpublished typescript.)

tion; one is crushed as taken from the highway.

Migrations of amphibians occur from time to time, both as young and adults, but are not often recorded in the literature.

This species is a sphagnum bog, pothole species. It may have increased in numbers locally or it may breed in extensive man-made ditches. This migration may have been occasioned by an explosion in local populations due to better living conditions in the shallow, warm ditches which are rich in aquatic insects of many species notably Trichoptera. The frogs may also have been looking for a suitable hibernating site.

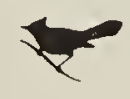

THOUSANDS OF AFRICAN CLAWED FROGS have been discovered in San Diego County's Sweetwater Reservoir and in drainage ditches in Orange County, California, according to the U.S. Fish and Wildlife Service. The agency has proposed regulations to control the importation of wildlife. The imported species sometimes breed rapidly in their new environments and threaten people, natural resources and native wildlife.

The African frog was originally brought into the U.S. for use as a pregancy test for humans, but has been replaced by more sophisticated methods. However, it has become established in Southern California where excess supplies were released or sold to pet stores. The frog first showed up in the reservoir in 1971 , and it may have been responsible for the decline in the local population of tree frogs. It is feared that the African variety may migrate to the Colorado River waterway where it could cause much more damage.

From Water Newsletter. July 24, 1974. 